\title{
Comparative Study of High-Resolution Computed Tomography Features in Coronavirus Disease-19 Pneumonia Patients in Different Stages of Adult Life
}

\author{
MOHAMED A. MOHAMED, M.D.*; HOUSSAM ELDIN H. ABD ELNABY, M.D.** and \\ MOSTAFA A.R. HUSSEIN, M.D.*** \\ The Departments of Radiodiagnosis*, Chest Diseases** and Internal Medicine***, Faculty of Medicine, Al-Azhar University
}

\begin{abstract}
Background: COVID-19 can lead to serious respiratory problems, including pneumonia, acute respiratory distress syndrome and even death. Therefore, chest computed tomography (CT) is considered a substantial tool for identifying infected patients. Moreover, it is helpful for follow-up and evaluation of the response to treatment.
\end{abstract}

Aim of the Study: The study aimed at comparing highresolution computed tomography (HRCT) chest features among adult COVID-19 pneumonia patients in relation to their age category.

Patients and Methods: This cross sectional study was conducted during the period from February 2021 to July 2021. It included 176 adult patients presented to the Outpatient Clinics of the Chest Diseases and Internal Medicine Departments, Bab Al-Sha'reia University Hospital, Cairo, with history and clinical picture suggesting COVID-19 infection, proved by positive reverse transcription real-time PCR (rt RT-PCR) test in their respiratory tract swabs, with their HRCT chest revealed radiological evidence of pneumonia. Studied patients were divided into three groups, depending on their age category; (1) Elderly group, (2) Middle-age group and (3) Young adults group.

Results: Ground glass opacities (GGOs), vascular dilatation and consolidation were the most frequent patterns in all studied groups. There were no statistically significant differences in HRCT chest radiological patterns between the elderly group and the young adults group, neither between the later and the middle-age group. Statistically significant differences were only present between the elderly and the middle-age groups, as the first showed higher frequencies of interlobular septal thickening, bronchiectatic changes and vascular dilatation ( $p$-values $=0.004,0.027$ and 0.018 respectively).

No statistically significant differences were observed among the study groups as regard the main pattern of abnormalities distribution. Bilateral and multilobar shadows were significantly abundant in the elderly group patients compared with the two other groups, while isolated left and unilobar affections were more frequent among the younger groups

Correspondence to: Dr. Houssam Eldin H. Abd Elnaby, E-Mail: drhoussam151979@gmail.com. compared with the elderly one. Unilateral right infiltrations were significantly more repetitive among the young adults group patients when compared with the elderly one, whilst bilobar affection showed non-significant variations among all groups.

Conclusion: The frequency of HRCT chest patterns in COVID-19 pneumonia do not vary greatly among patients in different stages of adult life. On the other hand, bilaterality, multilobar affection and heavy infiltrations are more associated with elderly people.

Key Words: High-resolution computed tomography - Coronavirus disease-19.

\section{Introduction}

CHEST imaging should be carefully requested in patients with suspected COVID-19 infection, not only to reduce the patients radiation exposure but also to reduce unnecessary exposure of other patients and healthcare workers and to rationalize the use of personal protective equipment and resources for disinfecting the patient care equipment [1].

Hence, chest CT should be performed in hospitalized and symptomatic patients with clinical worsening and/or patients who have comorbidities [1]. In these patients, CT is indicated mainly to assess the extent of the disease, to identify complications such as pulmonary thromboembolism or overlapping bacterial infection and to evaluate differential diagnoses [2].

Although (rt RT-PCR) is highly specific, recent studies have shown that it is only $30-60 \%$ sensitive [3], and it has been reported to be less sensitive than CT during the early course of the disease [4] The reason for that may be related to low patient viral load, improper sampling, timing of sampling or laboratory issues [3]. 
The CT hallmarks in COVID-19 pneumonia are bilateral distribution of ground glass opacities (GGOs) with or without consolidation in the posterior and peripheral lung, but the findings in later phases may include consolidations, linear opacities, "crazy-paving" pattern, "reversed halo" sign and vascular enlargement. The CT findings of COVID19 overlap with the CT findings of other diseases, in particular the viral pneumonia including influenza viruses, parainfluenza virus, adenovirus, respiratory syncytial virus, rhinovirus, human metapneumovirus, ... etc. There are differences as well as similarities in the CT features of COVID19 pneumonia compared with those of severe acute respiratory syndrome (SARS) and Middle East respiratory syndrome coronavirus (MERS-Cov) [5]. Notably, $56 \%$ of early presenting patients (02 days after the onset of symptoms) had a completely normal CT, although they may develop pulmonary shadows during the course of the disease, so postponing CT beyond the fourth day of symptoms is advisable, unless medical necessity is present [6].

As the disease progresses, the number and variety of lesions may rapidly increase and extend to the central areas [6]. During the disease recovery, the lesions are gradually absorbed over a period of weeks, with the possibility of formation of fibrotic stripes [7].

\section{Aim of the work:}

This study aimed at comparing HRCT chest features among adult COVID-19 pneumonia patients in relation to their age category.

\section{Patients and Methods}

This cross sectional study was conducted during the period from February 2021 to July 2021. Among 523 patients with clinical suspicion of COVID-19 infection assessed, only 176 patients escaped the exclusion criteria and were involved in the study. The mean age of the study population was 55.78 \pm 14.41 years (range $18-85$ years), 96 patients $(54.54 \%)$ of whom were females, while the other 80 patients $(45.46 \%)$ were males. The mean period passes between symptom onset and the performance of HRCT was 6.34 1.83 days (range 4-11 days).

Studied patients were divided into three groups, depending on their age, those groups were: (1) Elderly group ( $\leq 60$ years old) which included 95 patients, (2) Middle-age group ( $\geq 40-<60$ years) which included 53 patients and (3) Young adults group ( $\geq 18-<40$ years) which included 28 patients.

\section{Inclusion criteria:}

Patients presented to the Outpatient Clinics of the Chest Diseases and Internal Medicine Departments, Bab Al-Sha'reia University Hospital, Cairo, with history and clinical picture suggesting COVID19 infection, proved by positive (rt RT-PCR) test in their respiratory tract swabs, with their HRCT chest revealed radiological evidence of pneumonia.

\section{Exclusion criteria:}

Patients with any of the following were totally excluded from the study; proved COVID-19 infection with mild presentation which did not indicate radiological assessment, proved COVID-19 infection with normal HRCT chest, persistent pulmonary lesions in previous chest radiographs, chronic chest disease, documented recent bacterial or viral pneumonia in the last 3 months, decompensated cardiac, renal or hepatic disease, systemic medical conditions which may cause pulmonary shadows, e.g. connective tissue diseases, vasculitis, inflammatory bowel disease (IBD), ... etc, refusal to participate in the study and missed data or communication failure.

Ethical clearance was granted by Al-Azhar Faculty of Medicine Ethics and Research Committee. Detailed informed consents were obtained from all participants.

\section{Data collection:}

Personal data of the studied population were recorded including: Name, age, sex, residence, occupation, smoking habit, smoking index and other social habits of medical importance. Telephone number of each patient (or a close relative) was also recorded as an aid of communication. Full medical history was obtained to eliminate any condition listed in the exclusion criteria. Thorough clinical examination was performed to rule out any temporary medical problem which may interfere with the study results. After HRCT chest was done, the period between symptom onset and performing the CT was recorded.

\section{HRCT chest evaluation:}

All HRCT chest images were independently reviewed and scored by three chest radiologists with 10,12 and 15 years of experience, blinded to the clinical data and laboratory indicators. Images were taken using (Toshiba Aquilion multislice 64 channels CT Scanner, Toshiba Medical Systems Corp., Shimoishigami St, Otawara City, Tochigi, Japan).

All the radiologists were asked to register the abnormal radiological patterns for each patient, to 
record the main character of features distribution (whether peripheral or central), then to decide how many lobes are affected (unilobar, bilobar or multilobar) and to identify the affected lobe/lobes. This registration was applied in a specialized paper model designed for this study.

A semi-quantitative method was used to estimate the degree of pulmonary involvement by radiological patterns associated with COVID-19 pneumonia. Each of the 5 lung lobes was visually scored from 0 to 5 as follows: $0=$ no involvement, $1=<5 \%$ involvement, $2=5 \%-25 \%$ involvement, $3=$ $26 \%-49 \%$ involvement, $4=50 \%-75 \%$ involvement and $5=>75 \%$ involvement. The total HRCT chest score was the sum of the individual lobar scores and ranged from 0 (no involvement) to 25 (maximum involvement) [7]. The total score was recorded in details in another paper model.

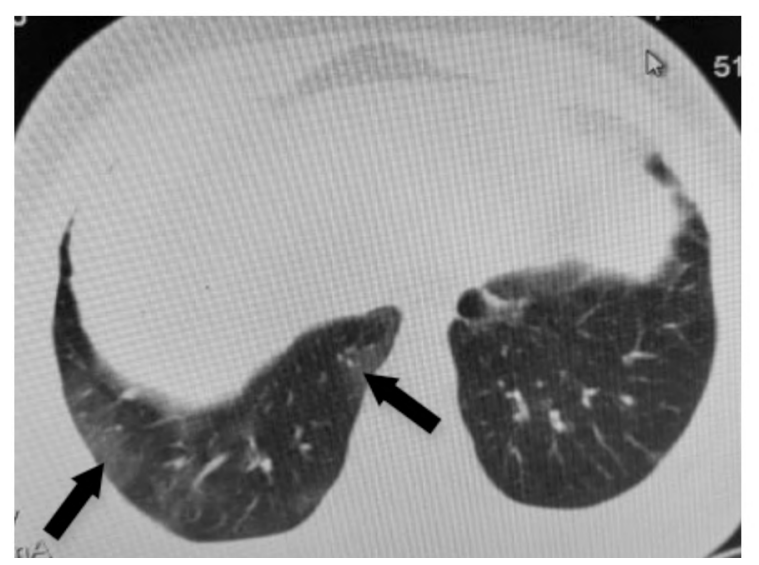

Fig. (1): Supleural GGOs (dark arrows) in a 28 years old female.

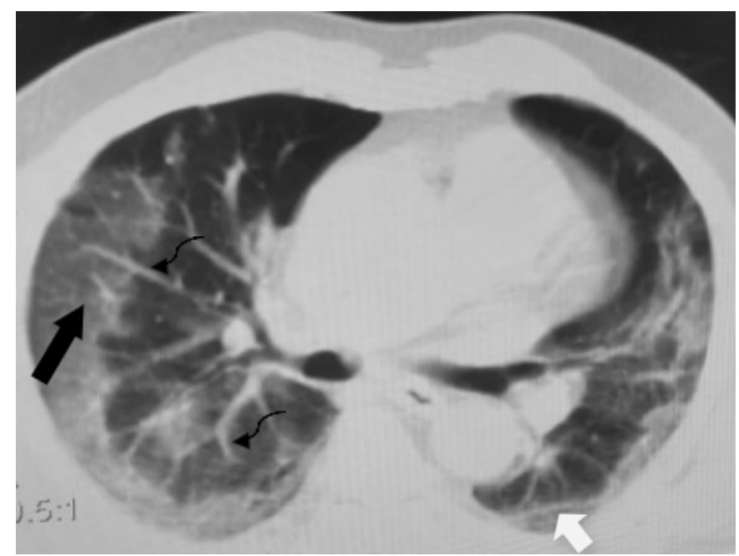

Fig. (3): Vascular dilatation (curved arrows), crazy paving pattern (dark arrow) and subpleural line (white arrow) in a 52 years old male.
Data submitted for statistical analysis had to be recognized by at least two of the examining radiologists.

\section{Statistical analysis:}

Statistical analysis of data was performed using Statistical Package for the Social Sciences (SPSS) version 25 (IBM corp., Armonk, NY, USA). Quantitative variables were expressed as mean \pm SD (standard deviation) and tested using two-tailed independent sample $t$-test. Qualitative variables were expressed as frequencies (percentages). Because of the inaccuracy of Chi-square test in studying small sample size $(<5)$, together with the fact that exact tests could adequately used to examine large sample size, we use the two-tailed Fisher's exact test to analyze qualitative variables. $p$-value at the level of significance was $<0.05$.

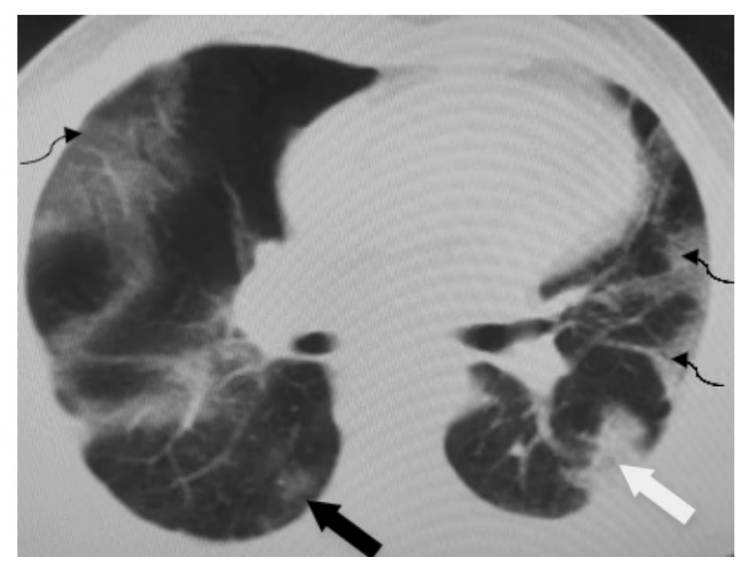

Fig. (2): GGOs (dark arrow), consolidation (white arrow) and crazy paving pattern (curved arrows) in a 72 years old male.



Fig. (4): Interlobular septal thickening (area within the bracket) in a 78 years old male. 


\section{Results}

Demographic and baseline data of the study population are displayed in (Table 1).

As shown in (Table 2), GGO was the most frequent radiological pattern among the studied patients $(98.86 \%)$, followed by vascular dilatation (83.52\%), consolidation $(64.2 \%)$, atelectasis (48.29\%), air bronchogram $(30.11 \%)$, subpleural line $(27.84 \%)$, crazy paving $(24.43 \%)$ and then other patterns. GGO, vascular dilatation and consolidation (arranged in descending manner) were also the most frequent patterns in all studied groups. There were no statistically significant differences in HRCT chest radiological patterns between the elderly group and the young adults group, neither between the later and the middle-age group. Statistically significant differences were only present between the elderly and the middle-age groups, as the first showed higher frequencies of interlobular septal thickening, bronchiectatic changes and vascular dilatation $(p$-values $=0.004,0.027$ and 0.018 respectively).

As enlightened in (Table 3), the peripheral distribution of HRCT chest patterns was found in the vast majority of the studied patients (98.29\%). As well, bilateral and multilobar affections were predominant (91.47\% and $84 \%$ respectively). The right lower lobe was the mostly infiltrated (95.45\%), followed by left lower one (94.31\%), then right upper lobe, left upper lobe and lastly right middle lobe with close percentages $(80.11 \%$, $78.4 \%$ and $77.84 \%$ respectively). No statistically significant differences were observed among the study groups as regard the main pattern of abnormalities distribution. Bilateral and multilobar shadows were significantly abundant in the elderly group patients compared with the two other groups, while isolated left and unilobar affections were more frequent among the younger groups compared with the elderly one. Unilateral right infiltrations were significantly more repetitive among the young adults group patients when compared with the elderly one, whilst bilobar affection showed nonsignificant variations among all groups.

Considering discrete lobar involvement, the affection of each of the right lung lobes was more frequent in the elderly group compared with the younger ones. The left upper lobe was significantly less affected in the youngest group compared with the oldest, while no significant differences were found among the three groups as regard the left lower lobe affection. For all HRCT chest patterns distribution, no statistically significant differences were present between the middle-age and the young adults groups.

As clarified in (Table 4), the mean HRCT chest score/patient for the whole study population was $8.39 \pm 4.58$. The right lower lobe had the highest mean HRCT chest score/lobe with $2.23 \pm 1.18$, while left upper lobe had the lowest with $1.32 \pm 0.95$. The mean HRCT chest score/patient was significantly higher in the elderly group compared with younger ones. On the other hand the means of the HRCT chest score/lobe for the right upper, right middle and left upper lobes were significantly higher in the elderly group compared with the remaining two groups. The mean HRCT chest score/lobe for the left lower lobe was significantly higher in the elderly group compared with the young adults group, while the means of HRCT chest score/lobe for the right lower lobe showed non-significant variations among the three groups. As regard the means of the HRCT chest score/patient and the means of HRCT chest score/discrete lobe, no statistically significant differences were present between the middle-age and the young adults groups.

Table (1): Demographic and baseline data of the study population.

\begin{tabular}{lllll}
\hline \multicolumn{1}{c}{$\begin{array}{c}\text { Study } \\
\text { Population }\end{array}$} & $\begin{array}{c}\text { All patients } \\
\mathrm{n}=176\end{array}$ & $\begin{array}{c}\text { Group 1 } \\
\mathrm{n}=95\end{array}$ & $\begin{array}{c}\text { Group 2 } \\
\mathrm{n}=53\end{array}$ & $\begin{array}{c}\text { Group 3 } \\
\mathrm{n}=28\end{array}$ \\
$\begin{array}{l}\text { Demographic } \\
\text { Data }\end{array}$ & & & & \\
\hline $\begin{array}{l}\text { Mean age/years } \pm \text { SD } \\
\text { Sex distribution: }\end{array}$ & $55.78 \pm 14.41$ & $67.12 \pm 5.6$ & $47.9 \pm 5.66$ & $32.25 \pm 5.51$ \\
$\quad$ Male & $80(45.46 \%)$ & $38(40 \%)$ & $28(52.83 \%)$ & $14(50 \%)$ \\
Female & $96(54.54 \%)$ & $57(60 \%)$ & $25(47.17 \%)$ & $14(50 \%)$ \\
Smoking habit: & & & & \\
$\quad \begin{array}{l}\text { Non-smoker } \\
\text { Smoker }\end{array}$ & $128(72.72 \%)$ & $75(78.94 \%)$ & $34(64.15 \%)$ & $19(67.85 \%)$ \\
Ex-smoker & $39(22.16 \%)$ & $14(14.73 \%)$ & $16(30.18 \%)$ & $9(32.15 \%)$ \\
\hline
\end{tabular}

SD: Standard deviation. 
Table (2): HRCT chest abnormal patterns among studied groups.

\begin{tabular}{|c|c|c|c|c|c|c|c|}
\hline $\begin{array}{l}\quad \begin{array}{l}\text { Study } \\
\text { Population }\end{array} \\
\text { HRCT } \\
\text { patterns }\end{array}$ & $\begin{array}{c}\text { All patients } \\
n=176\end{array}$ & $\begin{array}{c}\text { Group } \\
n=95\end{array}$ & $\underset{n=53}{\text { Group }} 2$ & $\begin{array}{c}\text { Group } \\
\mathrm{n}=28\end{array}$ & $\begin{array}{c}\text { Group } 1 \\
\text { versus } \\
\text { Group } 2\end{array}$ & $\begin{array}{l}\text { Group } 1 \\
\text { versus } \\
\text { Group } 3 \\
p \text {-value }\end{array}$ & $\begin{array}{c}\text { Group } 2 \\
\text { versus } \\
\text { Group } 3\end{array}$ \\
\hline GGO & $174(98.86 \%)$ & $95(100 \%)$ & $53(100 \%)$ & $26(92.85 \%)$ & 1.0 & 0.0503 & 0.11 \\
\hline Consol. & $113(64.2 \%)$ & $62(65.26 \%)$ & $35(66.03 \%)$ & $16(57.14 \%)$ & 1.0 & 0.5 & 0.47 \\
\hline $\mathrm{CP}$ & $43(24.43 \%)$ & $26(27.36 \%)$ & $11(20.75 \%)$ & $6(21.42 \%)$ & 0.43 & 0.62 & 1.0 \\
\hline ILST1 & $34(19.31 \%)$ & $26(27.36 \%)$ & $4(7.54 \%)$ & $4(14.28 \%)$ & $0.004 *$ & 0.21 & 0.43 \\
\hline ILST2 & $23(13 \%)$ & $12(12.63 \%)$ & $9(16.98 \%)$ & $2(7.14 \%)$ & 0.62 & 0.52 & 0.31 \\
\hline $\mathrm{AB}$ & $53(30.11 \%)$ & $32(33.68 \%)$ & $15(28.3 \%)$ & $6(21.42 \%)$ & 0.58 & 0.25 & 0.59 \\
\hline Bronchi. & $39(22.15 \%)$ & $28(29.47 \%)$ & $7(13.2 \%)$ & $4(14.28 \%)$ & $0.027 *$ & 0.14 & 1.0 \\
\hline Atelectasis & $85(48.29 \%)$ & $46(48.42 \%)$ & $26(49.05 \%)$ & $13(46.42 \%)$ & 1.0 & 1.0 & 1.0 \\
\hline VD & $147(83.52 \%)$ & $85(89.47 \%)$ & $39(73.58 \%)$ & $23(82.14 \%)$ & $0.018 *$ & 0.32 & 0.42 \\
\hline SPL & $49(27.84 \%)$ & $32(33.68 \%)$ & $11(20.75 \%)$ & $6(21.42 \%)$ & 0.13 & 0.25 & 1.0 \\
\hline Halo sign & $5(2.84 \%)$ & $3(3.15 \%)$ & $2(3.77 \%)$ & $0(0 \%)$ & 1.0 & 0.58 & 0.54 \\
\hline R. Halo sign & $22(12.5 \%)$ & $8(8.42 \%)$ & $8(15.09 \%)$ & $6(21.42 \%)$ & 0.27 & 0.08 & 0.54 \\
\hline Nodule & $39(22.15 \%)$ & $24(25.26 \%)$ & $11(20.75 \%)$ & $4(14.28 \%)$ & 0.55 & 0.3 & 0.55 \\
\hline Pl. eff. & $2(1.13 \%)$ & $2(2.1 \%)$ & $0(0 \%)$ & $0(0 \%)$ & 0.53 & 1.0 & 1.0 \\
\hline $\mathrm{LN}$ & $11(6.25 \%)$ & $9(9.47 \%)$ & $1(1.88 \%)$ & $1(3.57 \%)$ & 0.096 & 0.45 & 1.0 \\
\hline $\begin{array}{ll}\text { HRCT } & : \text { High-re } \\
\text { GGO } & \text { : Ground } \\
\text { Consolid. : Consoli } \\
\text { CP } & \text { : Crazy } \\
\text { ILST1 } & : \text { Interlob } \\
\text { ILST2 } & : \text { Interlob } \\
\text { AB } & : \text { Air bron } \\
p \text {-values } & \text { were calc }\end{array}$ & $\begin{array}{l}\text { solution compute } \\
\text { glass opacity. } \\
\text { dation. } \\
\text { aving. } \\
\text { pular septal thicke } \\
\text { ar septal thickeni } \\
\text { nchogram. } \\
\text { ulated by Fisher's }\end{array}$ & nography. & $\begin{array}{l}\text { Bro } \\
\text { VD } \\
\text { SPL } \\
\text { R. I } \\
\text { pl. } \\
\text { LN } \\
{ }_{*}^{*}\end{array}$ & $\begin{array}{l}\text { : Sub-pleur } \\
\text { sign : Reversed } \\
\text { : Pleural ef } \\
\text { : Lymph no } \\
\text { : Statistical }\end{array}$ & $\begin{array}{l}\text { changes. } \\
\text { ation. } \\
\text { ne. } \\
\text { sign. } \\
\text { s. } \\
\text { enlargement. } \\
\text { ignificant. }\end{array}$ & & \\
\hline
\end{tabular}

Table (3): HRCT chest abnormal patterns distribution among studied groups.

\begin{tabular}{|c|c|c|c|c|c|c|c|}
\hline $\begin{array}{l}\text { Study } \\
\text { Population } \\
\text { HRCT patterns } \\
\text { distribution }\end{array}$ & $\begin{array}{c}\text { All patients } \\
\mathrm{n}=176\end{array}$ & $\begin{array}{c}\text { Group } 1 \\
\mathrm{n}=95\end{array}$ & $\underset{n=53}{\text { Group }} 2$ & $\begin{array}{c}\text { Group } 3 \\
n=28\end{array}$ & $\begin{array}{l}\text { Group 1 } \\
\text { versus } \\
\text { Group } 2\end{array}$ & $\begin{array}{l}\text { Group } 1 \\
\text { versus } \\
\text { Group } 3 \\
p \text {-value }\end{array}$ & $\begin{array}{c}\text { Group } 2 \\
\text { versus } \\
\text { Group } 3\end{array}$ \\
\hline $\begin{array}{l}\text { Main distribution: } \\
\text { Peripheral } \\
\text { Central }\end{array}$ & $\begin{array}{l}173(98.29 \%) \\
3(1.71 \%)\end{array}$ & $\begin{array}{l}94(98.94 \%) \\
1(1.06 \%)\end{array}$ & $\begin{array}{l}52(98.11 \%) \\
1(1.89 \%)\end{array}$ & $\begin{array}{l}27(96.42 \%) \\
1(3.58 \%)\end{array}$ & 1.0 & 0.4 & 1.0 \\
\hline $\begin{array}{l}\text { Affected side: } \\
\quad \text { Bilateral } \\
\text { Right } \\
\text { Left }\end{array}$ & $\begin{array}{l}161(91.47 \%) \\
7(3.97 \%) \\
8(4.56 \%)\end{array}$ & $\begin{array}{l}94(98.94 \%) \\
1(1.06 \%) \\
0(0 \%)\end{array}$ & $\begin{array}{l}46(86.79 \%) \\
2(3.78 \%) \\
5(9.43 \%)\end{array}$ & $\begin{array}{l}21(75 \%) \\
4(14.28 \%) \\
3(10.72 \%)\end{array}$ & $\begin{array}{l}0.003 * \\
0.55 \\
0.005^{*}\end{array}$ & $\begin{array}{l}0.0001 * \\
0.009 * \\
0.01 *\end{array}$ & $\begin{array}{l}0.22 \\
0.17 \\
1.0\end{array}$ \\
\hline $\begin{array}{l}\text { Number of affected lobe } \\
\text { Uni-lobar } \\
\text { Bi-lobar } \\
\text { Multi-lobar }\end{array}$ & $\begin{array}{l}14(8 \%) \\
14(8 \%) \\
148(84 \%)\end{array}$ & $\begin{array}{l}0(0 \%) \\
6(6.32 \%) \\
89(93.68 \%)\end{array}$ & $\begin{array}{l}7(13.2 \%) \\
4(7.56 \%) \\
42(79.24 \%)\end{array}$ & $\begin{array}{l}7(25 \%) \\
4(14.28 \%) \\
17(60.71 \%)\end{array}$ & $\begin{array}{l}0.0005^{*} \\
1.0 \\
0.013^{*}\end{array}$ & $\begin{array}{l}<0.0001 * * \\
0.23 \\
<0.0001 * *\end{array}$ & $\begin{array}{l}0.22 \\
0.43 \\
0.11\end{array}$ \\
\hline $\begin{array}{l}\text { Discrete lobar affectior } \\
\text { Right upper } \\
\text { Right middle } \\
\text { Right lower } \\
\text { Left upper } \\
\text { Left lower }\end{array}$ & $\begin{array}{l}141(80.11 \%) \\
137(77.84 \%) \\
168(95.45 \%) \\
138(78.4 \%) \\
166(94.31 \%)\end{array}$ & $\begin{array}{l}86(90.52 \%) \\
83(87.36 \%) \\
95(100 \%) \\
81(85.26 \%) \\
91(95.78 \%)\end{array}$ & $\begin{array}{l}39(73.58 \%) \\
38(71.69 \%) \\
48(90.56 \%) \\
40(75.47 \%) \\
51(96.22 \%)\end{array}$ & $\begin{array}{l}16(57.14 \%) \\
16(57.14 \%) \\
25(89.28 \%) \\
17(60.71 \%) \\
24(85.71 \%)\end{array}$ & $\begin{array}{l}0.009^{*} \\
0.025^{*} \\
0.005^{*} \\
0.18 \\
1.0\end{array}$ & $\begin{array}{l}0.0001 * \\
0.0009 * \\
0.01 * \\
0.007 * \\
0.07\end{array}$ & $\begin{array}{l}0.14 \\
0.22 \\
1.0 \\
0.2 \\
0.17\end{array}$ \\
\hline
\end{tabular}

HRCT: High-resolution computed tomography. *: Statistically significant. **: Statistically highly significant. $p$-values were calculated by Fisher's exact test. 
Table (4): HRCT chest score among studied groups.

\begin{tabular}{|c|c|c|c|c|c|c|c|}
\hline $\begin{array}{c}\text { Study } \\
\text { Population }\end{array}$ & $\begin{array}{l}\text { All patients } \\
\mathrm{n}=176\end{array}$ & $\underset{n=95}{\text { Group }} 1$ & $\underset{n=53}{\text { Group }} 2$ & $\underset{\mathrm{n}=28}{\operatorname{Group}} 3$ & $\begin{array}{l}\text { Group } 1 \\
\text { versus } \\
\text { Group } 2\end{array}$ & $\begin{array}{c}\text { Group } 1 \\
\text { versus } \\
\text { Group } 3 \\
p \text {-value }\end{array}$ & $\begin{array}{c}\text { Group } 2 \\
\text { versus } \\
\text { Group } 3\end{array}$ \\
\hline $\begin{array}{l}\text { Mean HRCT } \\
\text { score } \pm \text { SD per patient }\end{array}$ & $8.39 \pm 4.58$ & $9.47 \pm 4.78$ & $7.51 \pm 3.81$ & $6.43 \pm 4.16$ & $0.011^{*}$ & $0.003 *$ & 0.24 \\
\hline \multicolumn{8}{|l|}{$\begin{array}{l}\text { Mean HRCT score } \pm S D \\
\text { per discrete lobe: }\end{array}$} \\
\hline Right upper & $1.35 \pm 0.99$ & $1.65 \pm 1.0$ & $1.09 \pm 0.85$ & $0.86 \pm 0.87$ & $0.0008 *$ & $0.0002 *$ & 0.24 \\
\hline Right middle & $1.4 \pm 1.07$ & $1.68 \pm 1.13$ & $1.19 \pm 0.87$ & $0.89 \pm 0.89$ & $0.006^{*}$ & $0.001 *$ & 0.15 \\
\hline Right lower & $2.23 \pm 1.18$ & $2.41 \pm 1.12$ & $2.02 \pm 1.22$ & $2.07 \pm 1.22$ & 0.052 & 0.17 & 0.85 \\
\hline Left upper & $1.32 \pm 0.95$ & $1.55 \pm 0.98$ & $1.11 \pm 0.79$ & $0.96 \pm 0.94$ & $0.006^{*}$ & $0.006^{*}$ & 0.46 \\
\hline Left lower & $2.06 \pm 1.11$ & $2.18 \pm 1.15$ & $2.09 \pm 0.99$ & $1.64 \pm 1.07$ & 0.65 & $0.03 *$ & 0.06 \\
\hline
\end{tabular}

HRCT: High-resolution computed tomography. A: Age. SD: Standard deviation. *: Statistically significant. $p$-values were calculated by independent sample $t$-test.

\section{Discussion}

In spite of the numerous discrepancies about many of COVID-19 fields, the classic radiological CT pattern of bilateral subpleural GGOs with lower lobar predominance remains one of the few untouchable concepts throughout the pandemic era.

In our study we recorded GGOs as the most frequent abnormal radiological pattern in COVID19 pneumonia patients $(98.86 \%)$, followed by vascular dilatation $(83.52 \%)$, consolidation $(64.2 \%)$, atelectasis $(48.29 \%)$, air bronchogram sign $(30.11 \%)$, subpleural line pattern $(27.84 \%)$, crazy paving pattern $(24.43 \%)$, bronchiectatic changes and pulmonary nodulations $(22.15 \%)$, interlobular septal thickening (19.31\%), interlobar septal thickening (13\%), reversed halo sign $(12.5 \%)$, mediastinal and/or hilar lymphadenopathy (6.25\%), halo sign $(2.84 \%)$ and lastly pleural effusion $(1.13 \%)$. The most of these findings are greatly matching with a meta-analysis involved 13 studies (2738 COVID-19 patients), in which typical CT signs were GGOs $(83.31 \%)$, GGOs with consolidation $(58.42 \%)$, interlobular septal thickening $(48.46 \%)$ and air bronchograms (46.46\%). Other CT signs included crazy paving pattern $(14.81 \%)$, pleural effusion (5.88\%), bronchiectasis $(5.42 \%)$ and lymphadenopathy (3.38\%) [8].

Our results also agree to a considerable extent with those of a larger meta-analysis (45 studies comprising 4410 COVID-19 patients), which reported isolated GGOs in $50.2 \%$ of patients, mixed GGOs and consolidation in $44.2 \%$, pulmonary vascular enlargement in $64 \%$, intralobular septal thickening in $60 \%$, air bronchogram in $41.2 \%$, subpleural lines in $25 \%$, crazy paving in $19.5 \%$, bronchiectasis in $18 \%$, interlobar septal thickening in $15 \%$, pulmonary nodules in $7.8 \%$, lymphadenopathy in 5.4\% and pleural effusion in 5\% [9].

Corresponding to our findings, a cross-sectional multicenter study involving 220 COVID-19 pneumonia patients, with average age of 49.19 years, reported GGOs, consolidation, crazy paving, vascular thickening, traction bronchiectasis and reversed halo sign as common CT patterns, while halo sign, masses, tree in-bud-pattern and cysts were considered uncommon features [10].

Sailing with the same stream, Caruso and coworkers reported GGOs in $100 \%$ and subsegmental vessel enlargement $(>3 \mathrm{~mm})$ in $89 \%$ of their 58 COVID-19 patients [11]. At the same time, most of our results are close to a small Chinese study included 53 patients, which recorded GGOs in $98.11 \%$, consolidation in $45.3 \%$, crazy-paving in $26.4 \%$, bronchiectasis in $22.6 \%$ and pleural effusion in $1.9 \%$. However, they recorded lower frequencies of atelectasis, air bronchogram and interlobular septal thickening among their patients $(13.2 \%$, $11.3 \%$ and $9.4 \%$ respectively) compared with ours [12].

Although they had 27 patients with completely normal CT among their 121 patients, considering the pneumonic patients in Bernheim et al., work will reveal some similarities to our results in the frequencies of GGOs $(96.8 \%)$, consolidation $(58.51 \%)$ and pleural effusion (1.06\%). However, they reported much lower frequencies of crazy paving $(6.38 \%)$, reversed halo sign $(2.12 \%)$ and bronchiectasis (1.06\%) [6].

In an Iranian systemic review aimed at comparing chest CT findings of COVID-19 pneumonia 
between pediatric and adult patients in 15 different studies (a total of 878 patients, 849 of them were adults), Azadbakht and his colleagues reported GGOs in $68.4 \%$ of his adult patients, consolidation in $33.7 \%$, crazy paving pattern in $27.7 \%$, nodular opacities in $9.2 \%$, pleural effusion in $5.5 \%$ and lymphadenopathy in $2.4 \%$. Those findings meet ours in some points, while oppose them in others [13].

Likewise, one of the early COVID-19 studies which included limited number of participants (only 17 patients), with a median age of 48.6 years and a median period of 4.04 days from symptom onset to HRCT, reported GGOs in $100 \%$ of patients and combined GGOs and consolidation in $29.41 \%$. Air bronchogram was identified in $17.64 \%$, while none of the patients had tree-in-bud pattern, cavitation or pleural effusion [14].

Another Chinese small study with 46 COVID19 patients presented by viral pneumonia, observed that all the lesions were exhibited as GGOs with or without consolidation, with high proportions of supplying pulmonary artery dilation $(89.13 \%)$ and air bronchogram $(69.57 \%)$ were found. Other findings included thickening of the intralobular interstitium (28.26\%), halo sign $(26.08 \%)$, interlobar septal thickening (2.1\%) and pleural effusion $(2.1 \%)$. Cavitation, calcification and lymphadelopathy were not detected within the studied patients [15]. Those findings accord with ours in many aspects, in spite of showing diversity in the frequencies of some abnormal chest CT patterns.

An Egyptian study included 30 confirmed COVID-19 patients found that the most common CT features detected were GGOs $(93.3 \%)$, followed by subpleural linear abnormality $(53.3 \%)$, consolidation with air bronchogram $(23.3 \%)$, bronchial wall thickening $(16.7 \%)$, crazy paving pattern $(13.3 \%)$ and discrete nodules surrounded by ground glass appearance $(10 \%)$. Only $3.3 \%$ of the patients had pleural effusion. No cavitary lesions or specific lymph nodes were detected in any of the examined patients [16]. Those results are closer rather than being far from ours.

In the current work we observed that the peripheral distribution of HRCT chest patterns was found in the vast majority of the studied patients (98.29\%). Likewise, bilateral and multilobar affections were predominant $(91.47 \%$ and $84 \%$ respectively). The right lower lobe was the mostly infiltrated $(95.45 \%)$, followed by left lower one (94.31\%), then right upper lobe, left upper lobe and lastly right middle lobe with close percentages (80.11\%, $78.4 \%$ and $77.84 \%$ respectively).
Most of these findings typically match with those of a large study which observed that most anatomic distributions of COVID-19 pneumonia were bilateral lung infection $(78.2 \%)$ with peripheral distribution $(76.95 \%)$. The incidences were highest in the right lower lobe $(87.21 \%)$, left lower lobe $(81.41 \%)$ and bilateral lower lobes $(65.22 \%)$. The right upper lobe $(65.22 \%)$, right middle lobe $(54.95 \%)$ and left upper lobe $(69.43 \%)$ were also commonly involved. The incidence of bilateral upper lobes affection was $60.87 \%$. A considerable proportion of patients had three or more lobes involved $(70.81 \%)$ [8]

Our study findings agree with the observations of Sabri et al., who demonstrated multilobar affection in $84.54 \%$ of patients and peripheral/subpleural affection in $92.27 \%$ [10] . Our results also run parallel to an Italian study in which multilobar and posterior involvement were reported in $93 \%$ of the study patients, with bilateral pneumonia in $91 \%$ of them [11]. Another study recorded a more or less identical frequency of multilobar involvement to ours $(84.9 \%)$ [12].

Our results totally merge with those of Bernheim et al., as they pointed the right lower lobe to be the mostly affected ( $84 \%)$, followed by the left lower lobe $(80.85 \%)$, with the right middle lobe was the least affected (53.19\%). However, they recorded lower frequencies of bilateral disease (77.65\%) and multilobar involvement (65.95\%), higher frequencies of unilobar (19.14\%) and bilobar (14.89\%) infiltrations compared with ours [6].

Similarly, they coincide with those of Omar and his colleagues who concluded that the lung lesions in COVID-19 pneumonia showed diffuse, basal and subpleural involvement with less affection of the upper lobes [16]. The findings obtained by this study are relatively near to those of a metaanalysis of 19 retrospective studies (1332 COVID19 patients) which that the proportion of peripheral lung distribution was $74 \%$, diffuse distribution was $19 \%$, unifocal involvement was $9 \%$, multifocal involvement was $57 \%$, unilateral affection was $17 \%$ and bilateral affection was $83 \%$ [17]

In this study we observed higher frequencies of interlobular septal thickening, bronchiectatic changes and vascular dilatation among the patients of the elderly group compared with the middleage one ( $p$-values $=0.004,0.027$ and 0.018 respectively). As well, bilateral and multilobar shadows were significantly abundant in the elderly group patients compared with the middle-age and young adults groups. The affection of each of the right lung lobes was more frequent in the elderly group 
compared with the younger ones. The left upper lobe was significantly less affected in the youngest group compared with the oldest, while no significant differences among the three groups were found as regard the left lower lobe affection.

These results typically match with an analogous study with four different age groups, one of them was a pediatric one, which detected a higher incidence of bilateral lung disease in the senior group compared with other groups, as well as exploring statistically significant differences among different age groups as regard the frequency of lobe involvement including right upper lobe, right middle lobe, right lower lobe and left upper lobe. This study also merges with us in observing non-significant differences in CT features of patchy GGOs, consolidation and nodules among the studied groups [18].

In contrary to our findings, a similarly constructed study revealed that multilobar involvement was significantly abundant among elderly and middle-age groups in comparison with the young adults group ( $p$-values $=<0.001$ and $<0.001$ respectively). Moreover, the youngest group showed a significant lower frequencies when compared with the elderly and middle-age groups as regard crazy paving pattern ( $p$-values $=<0.001$ and $<0.001 \mathrm{re}$ spectively) and bronchiectasis ( $p$-values $=0.032$ and 0.004 respectively). Vascular dilatation was found to be more frequent in the elderly group compared with the young adults group $(p$-value $=$ 0.002) [19]

\section{Conclusion:}

The frequency of HRCT chest patterns in COVID-19 pneumonia do not vary greatly among patients in different stages of adult life. On the other hand, bilaterality, multilobar affection and heavy infiltrations are more associated with elderly people.

\section{References}

1- RUBIN G.D., RYERSON C.J., HARAMATI L.B., et al.: The role of chest imaging in patient management during the COVID-19 pandemic: A multinational consensus statement from the fleischner society. Radiology, 296 (1): 172-180, 2020.

2- DE FARIAS L.P.G., FONSECA E.K.U.N., STRABELLI D.G., et al.: Imaging findings in COVID-19 pneumonia. Clinics (Sao Paulo), 75: e2027, 2020.

3- FANG Y., ZHANG H., XIE J., et al.: Sensitivity of chest CT for COVID-19: Comparison to RT-PCR. Radiology, 296 (2): 111-117, 2020.

4- FANG Y., ZHANG H., XU Y., et al.: CT manifestations of two cases of 2019 novel coronavirus (2019-nCoV) pneumonia. Radiology, 295 (1): 208-209, 2020.
5- CAROTTI M., SALAFFI F., SARZI-PUTTINI P., et al.: Chest CT features of coronavirus disease 2019 (COVID 19) pneumonia: Key points for radiologists. La Radiologia Medica., 125 (7): 1-11, 2020.

6- BERNHEIM A., MEI X., HUANG M., et al.: Chest CT findings in coronavirus disease-19 (COVID-19): Relationship to duration of infection. Radiology, 295 (3): 685691,2020 .

7- LI K., WU J., WU F., et al.: The clinical and chest CT features associated with severe and critical COVID-19 pneumonia. Invest. Radiol., 55 (6): 327-331, 2020.

8- BAO C., LIU X., ZHANG H., LI Y. and LIU J.: Coronavirus disease 2019 (COVID-19) CT findings: A systematic review and meta-analysis. J. Am. Coll. Radiol., 17 (6): 701-709, 2020.

9- OJHA V., MANI A., PANDEY N.N., SHARMA S. and KUMAR S.: CT in coronavirus disease 2019 (COVID19): a systematic review of chest CT findings in 4410 adult patients. Eur. Radiol., 30 (11): 6129-6138, 2020.

10- SABRI Y.Y., NASSEF A.A., IBRAHIM I.M.H., ABD EL MAGEED M.R. and KHAIRY M.A.: CT chest for COVID-19, a multicenter study-experience with 220 Egyptian patients. Egypt. J. Radiol. Nucl. Med., 51 (1): 144, 2020.

11- CARUSO D., ZERUNIAN M., POLICI M., et al.: Chest CT Features of COVID-19 in Rome, Italy. Radiology, 296 (2): 79-85, 2020.

12- XIANG C., LU J., ZHOU J., GUAN L., YANG C. and CHAI C.: CT findings in a novel coronavirus disease (COVID-19) pneumonia at initial presentation. Bio. Med. Research International, 2020 (7): 1-10, 2020.

13-AZADBAKHT J., HAGHI-AMINJAN H. and FARHOOD B.: Chest CT findings of COVID-19-infected patients, are there differences between pediatric and adult patients? A systematic review. Egypt. J. Radiol. Nucl. Med., 51 (1): 145, 2020.

14- ZHANG S., LI H., HUANG S., YOU W. and SUN H.: High-resolution CT features of 17 cases of Corona virus disease 2019 in Sichuan province, China. Eur. Respir. J., 55 (4): 2000334, 2020.

15- HU Q., GUAN H., SUN Z., et al.: Early CT features and temporal lung changes in COVID-19 pneumonia in Wuhan, China. Eur. J. Radiol., 128: 109017, 2020.

16- OMAR S., MOTAWEA A.M. and YASIN R.: Highresolution CT features of COVID-19 pneumonia in confirmed cases. Egypt. J. Radiol. Nucl. Med., 51 (1): 121, 2020.

17- YANG H., LAN Y., YAO X., LIN S. and XIE B.: The chest CT features of coronavirus disease 2019 (COVID19) in China: A meta-analysis of 19 retrospective studies. Virol. J., 17 (1): 159, 2020.

18- LI W., FANG Y., LIAO J., et al.: Clinical and CT features of the COVID 19 infection: Comparison among four different age groups. Eur. Geriatr. Med., 11 (5): 843-850, 2020.

19-WANG J., ZHU X., XU Z., et al.: Clinical and CT findings of COVID-19: Differences among three age groups. BMC. Infectious Diseases, 20: 434, 2020 


\section{دراسة مقارنة لخصائص التصوير المقطعى الحاسوبى عالى التباين

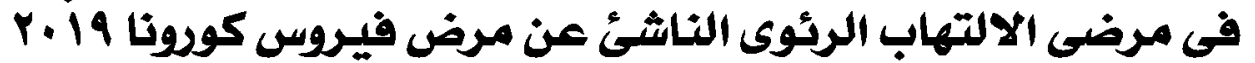

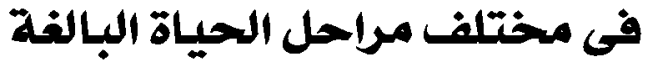

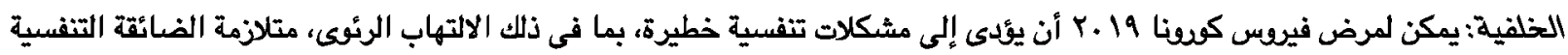

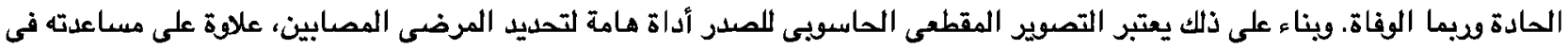
المتابعة وتقييم الاستجابة للعلاج.

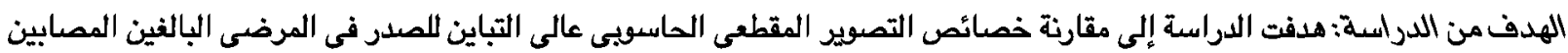

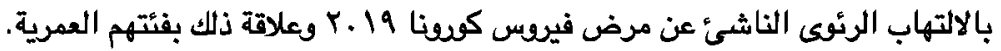

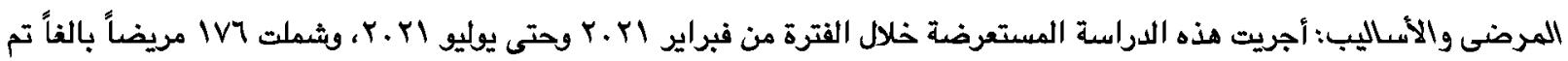

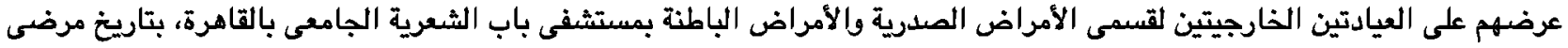

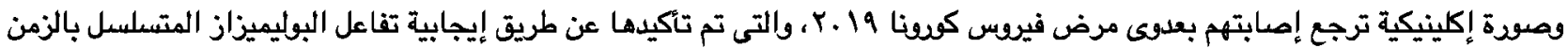



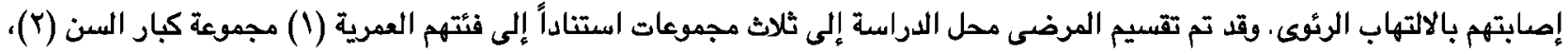
مجموعة متوسطى العمر (广) ومجموعة الشباب.

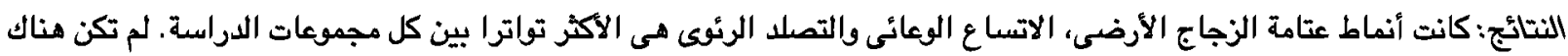

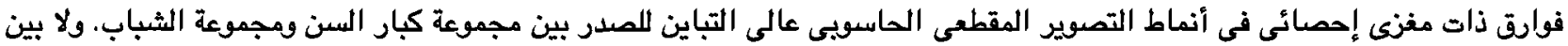

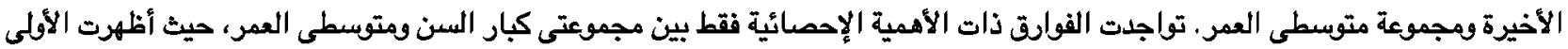


الترتيب).

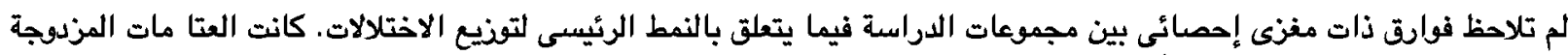

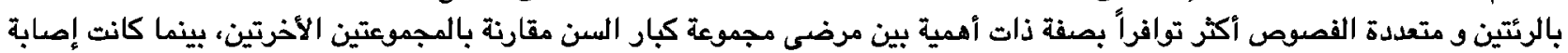

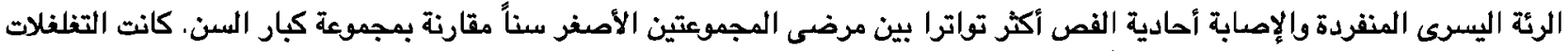


ثثائية الفص اختلافات غير ذات أهمية بين كل المجموعات.

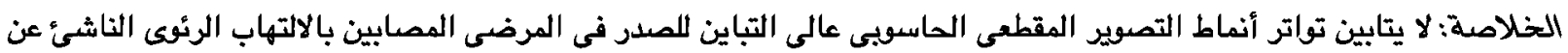

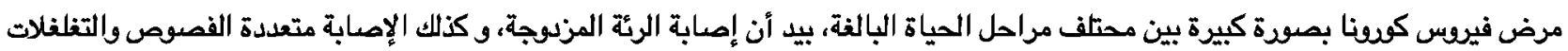
الكثيفة تعد أكثر ارتباطاً بكبار السن. 